\title{
Binding Models of Flavonols to Human Vascular Endothelial Grow th Factor Receptor 2
}

\author{
Jee-Young Lee, Ki-Woong Jeong, Woonghee Kim, Yong Seok Heo, and Yangmee Kim \\ Department of Bioscience and Biotechnology Bion folecular Informatics Center, Konkuk Lniversity, \\ Seoul 1+3-701, Korea. 'E-mail: whimólkonkuk ackr. \\ ${ }^{\dagger}$ Department of Chemistry, Konkth Lniversitv, Seoul 143-701, Korea \\ Received Jine 26. 2009, Accepted Jine 30. 2009
}

\begin{abstract}
Human vascular endothelial growth factor receptor 2 (hVEGFR2) is an important signaling protein involved in angiogenesis and attractive drug target in cancer therapy. It has been reported that flavonols, a class of flavonoids, have anti-angiogenic activity in various cancer cell lines. We performed receptor-oriented pharnacophore based in silico screening for identification of hVEGFR2 inhibitors from flavonol database. By comparing with three X-ray complex structures of hVEGFR2 and its inlubitors, we evaluated the specific interactions between inhibitors and receptors and detemined a single pharmacophore map. This map consisted of four features, a hydrogen bonding acceptor (HBA) on Cys917, wo hydrogen bonding donors on Glu917 (HBD1) and Glu883 (HBD2), and one hydrophobic interaction (Lipo) with Va1846, Ala864, Val897, Val914 and Phel045 of hVEGFR2. Using this map, we searched a flavonol database including 9 typical tlavonols and proposed that five flavonols, kaempferol, quercetin, fisetin, morin, and rhanmetin can be potent inhibitors of hVEGFR2. 3-OH of C-ring and 4'-OH of B-ring of flavonols are the essential features for hVEGFR2 inhibition. This study will be helpful for understanding the mechanism of inhibition of hVEGFR2 by natural products.
\end{abstract}

Key Words: VEGFR2. Flavonoid. Anticancer drug. in silico screening. Pharmacophore

\section{Introduction}

Vascular endothelial growth factor (VEGF) is a sub-family of growth factors and important signaling proteins involved in both vasculogenesis and angiogenesis. ' Vasculogenesis and angiogenesis are similar to process of blood vessel fonmation but these are different in one aspect: Angiogenesis represents the formation of new blood vessels from pre-existing ones. whereas vasculogenesis is used for the formation of new blood vessels by a de novo production of endothelial cells. ${ }^{2.3}$ These play an important role in the pathogenesis of a variety of disorders such as tumor growth, proliferative retinopathies, and rhemmatoid arthritis. ${ }^{4-6}$ The biological effects of VEGF are mediated by two receptor tyrosine kinases (RTKs). VEGFRl and VEGFR2 kinase. ${ }^{8}$ It has been demonstrated that the inhibition of VEGF signaling not only blocks angiogenesis in tumors but can also change or destroy tumor. As a result. VEGFR2 is an attractive target for biologically based cancer therapies.

Inhibition of the VEGFR2 called as kinase insert domain receptor (KDR) signaling pathway can provide an anti-angiogenic effect in human cancers and recently several drugs are demonstrated by the FDA approval of the anti-VEGF drugs. ${ }^{\text {lit/3 }}$

Flavonoids are common constituents of plants and are widely used in medicine for treatment of several human diseases. ${ }^{\mid 4-j 6}$ Recently it has been reported that flavonoids inlibit angiogenesis and proliferation of various tumor cells and endothelial cells by inhibition of ty rosine kinase family including VEGFR 1 and VEGFR2 ${ }^{17,18}$ It is well known that flavonoids show inhibitory activity against several kinases and the X-ray complex structure of flavonoids or flavonoid derived compounds and kinase have been released. ${ }^{15 .}$ Therefore flavonoids can be inhibitors of VEGFR2 by inhibition of its kinase domain.
In this study, we perfonmed receptor-oriented phannacophore based in silico screening in order to understand the interactions between kinase domain of human VEGFR2 (hVEGFR2) and flavonols which are a family of flavonoids. Since some of flavonols are known to have anti-angiogenic effects on several cancer cells ${ }^{1 \% 18}$ this study will be helpful to understand the mechanism of their actions against kinase and these flavonols can be good lead natural compounds for the further anti-cancer drug development.

\section{Methods}

A list of features. including hydrogen bond donors (HBDs). hydrogen bond acceptors (HBAs) and lipophilicity (Lipo), were used to determine the pharmacophore map. Maps were generated with the excluded volume for heavy atoms. which is the forbidden area in the active site that defines its shape. To account for excluded volume regions occupied by heavy atoms in the receptor, an exclusion model was generated for the active site and surrounding receptor regions. Each atom of the receptor selected for inclusion in the model was presented as an exclusion point. We superimposed X-ray complex structures of inhibitorhVEGFR2 and complex structure of cyclin dependent kinase 6 (CDK6) and flavonoid fisetin ( $1 \mathrm{XO} 2$.pdb) at the center of the ATP binding site. Then we defined specific interactions between hVEGFR2 and its inhibitors. Based on this information, we determined a single pharmacophore map which expressed effectively the binding model of hVEGFR2 and inhibitors. We searched the flavonol library which included 9 typical flavonols as listed in Table $\mathrm{l}$ and calculated ligand score (LigScore) of hit flavonols. Conputations were performed on a Linux environment using the DS Modeling 2.I (Accelñ's Inc.. San Diego, CA). 
Table 1. Structures of l7avenols hased on the position of their substituents and ligscore of hit liavomels

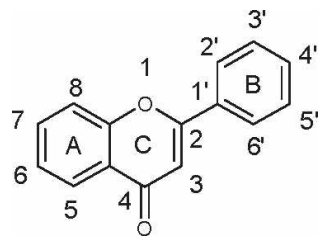

\begin{tabular}{|c|c|c|c|c|c|c|c|c|}
\hline \multirow{2}{*}{ Flavonols } & \multicolumn{7}{|c|}{ l'osition ol substituents } & \multirow{2}{*}{$\begin{array}{l}\text { Iig- } \\
\text { Score }\end{array}$} \\
\hline & 3 & 5 & 7 & $2^{\circ}$ & 3 & $4^{\circ}$ & 5 & \\
\hline Galangin & $\mathrm{OH}$ & OIJ & OI & II & HI & $\mathrm{H}$ & $\mathrm{H}$ & - \\
\hline$\underline{\text { Kamplemplerol }}$ & () $\mathrm{H}$ & OII & OII & $\underline{\text { II }}$ & $\underline{\mathrm{H}}$ & ( $\mathrm{OII}$ & $\underline{H}$ & 5.03 \\
\hline Quertcetin & $\overline{\mathrm{OH}}$ & $\overline{(011}$ & $\overline{(911}$ & $\underline{\text { II }}$ & $\overline{\mathrm{OH}}$ & $\overline{(311}$ & $\bar{j}$ & 5.75 \\
\hline Mỵricetin & $\mathrm{OH}$ & OII & OI & II & $\mathrm{OH}$ & OI & OII & - \\
\hline Fisetin & () H & $\underline{\mathrm{H}}$ & OII & II & $\mathrm{OH}$ & (II & H & 5.78 \\
\hline Morin & $\underline{\mathrm{OH}}$ & $\underline{\mathrm{OII}}$ & $\overline{\mathrm{OII}}$ & $\underline{\mathrm{OH}}$ & $\underline{\text { II }}$ & $\underline{\mathrm{OII}}$ & $\underline{\mathrm{H}}$ & 5.21 \\
\hline Kaemplieride & $\mathrm{OH}$ & OII & OI & II & HI & OM & $\mathrm{H}$ & - \\
\hline Rhammetim & ()H & OII & $(\mathrm{O}-\mathrm{Me}$ & II & $\mathrm{OH}$ & OII & $\underline{H}$ & 5.60 \\
\hline Pachypodol & $\mathrm{O}-\mathrm{Me}$ & OII & $\mathrm{O}-\mathrm{Mc}$ & II & $\mathrm{O} M \mathrm{Mc}$ & OII & $\mathrm{H}$ & \\
\hline
\end{tabular}

\section{Results and Discussion}

We selected X-ray complex structures of inhibitor and hVEGFR2 (lY6B.pdb. 2OH4,pdb, and 3BE2.pdb) based on the resolution of X-ray crstallography and superimposed thesc struclures to compare the binding model belween inhibitors and VEGFR2. ${ }^{21-2.1}$ In three X-ray structures. inhibitors commonly formed three hydrogen bonds with backbone amide proton of Cys917 and side chain oxygen of Glu915 and Glu883. respectively, and one hydrophobic interaction with Val846. Ala864. Val897. Val9l4 and Phe l(145 of hVEGFR2. In the X-ray structure of flavonoid fisetin and cyclin dependent kinase 6 (CDK6). fisctin had four hydrogen bonding interactions with backbone anide proton of Val 101, side chain oxygens of Glu99 and Glu6l. and side chain nitrogen of Gln 49 of CDK6. respectively. Anong these four hydrogen bonds. three hydrogen bonds formed with Val 101 . Glu\%9. and Glu6I in cyclin cortesponds to those with Cys917. Glu915, and Glu883 in VEGFR2, respectively. Therelore. threc hydrogen bonding interactions and one hydrophobic interaction are important features for binding to hVEGFR2. The supcrimposed structures of know n hVEGFR2 inlibitors and fisctin from CDK6 are depicied in Figure I.

We defined a single plarmacophore map including four chemical features: a hỵdrogen bonding acceptor (HBA) on Cys917. two hydrogen bonding donors on Glu917 (HBDl) and Glu883 (HIBD2). and onc hydrophobic interaction (Lipo) with five lysdrophobic residues. ${ }^{2.25}$ Pharmacophore map are depicted in Figure 2. We searched the flavonol library and among 9 flavonols. five (kacmpferol. quercetin. fisctin. miorin. and rhamnetin) were hit by this pharmacophore map as candidates of hVEGFR2 inlibitors. The 2D structures of 9 flavonols and LigScore of these hils are listed in Table 1.

Flavonols are a class of flavonoids and present in a wide varicty of regelables and fruits. ${ }^{26}$ They use the 3-hy droxy[la-
(A)

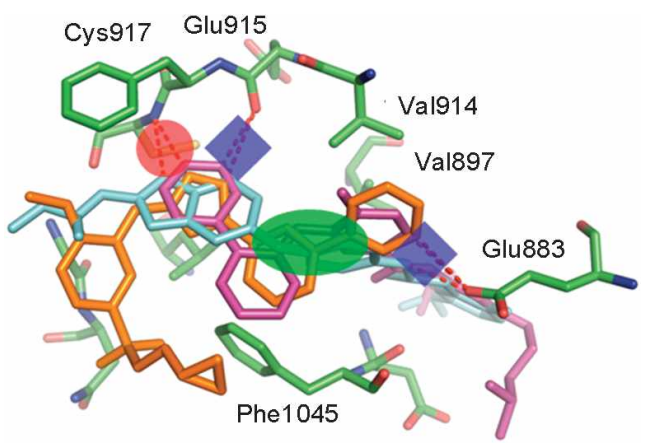

(B)

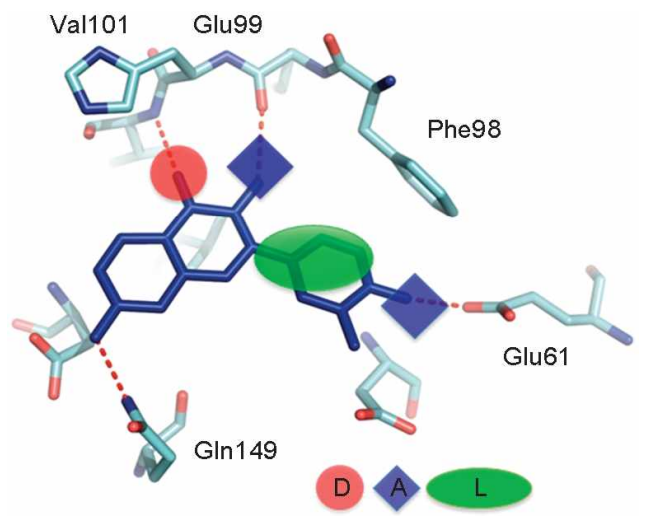

Figune 1. Interaction models ol $(\Lambda)$ three hVl:Gl R2 inllibitors and hVI:GI'R2 laken trem X-ray complex structures ol hVl:GIiR2 (IY-

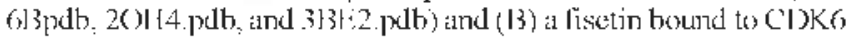
(1XO2.pdb). I) reprensents hy drogen bonding donor, $\triangle$ reprensents hy drogen bonding aceptor. and I reprensents hydrophobic interaction.

(A)

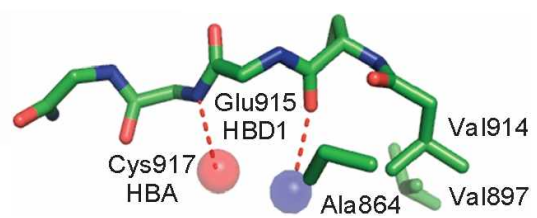

(B)

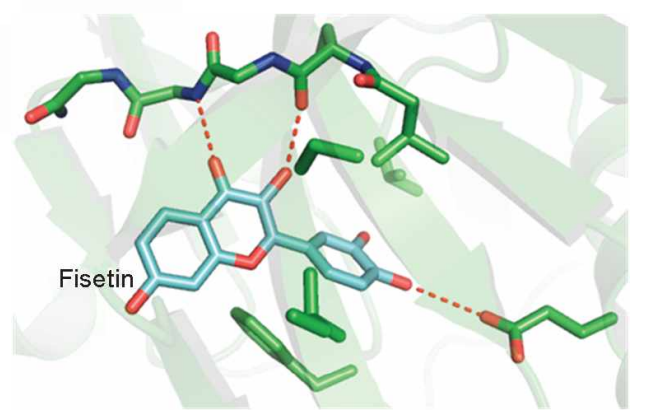

Figure 2. ( $A$ ) $\triangle$ single pham

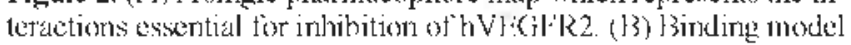
of tisetin and hVI GFR 2 determined by in silice sereening using this phamacophore map. 
(A)

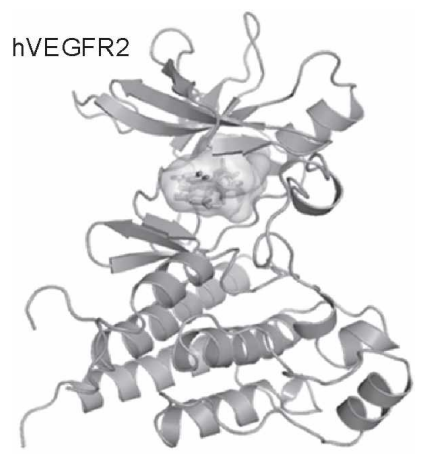

(B)

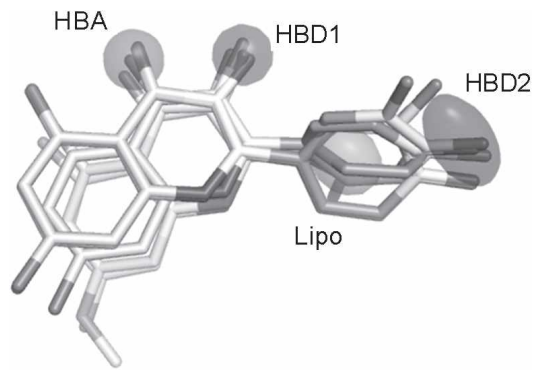

Figure 3. (A) Structure of hVEGFR2 in complex with 5 hit flatonols. (B) Binding models of 5 dlavonols shown with pharmacophore map.

vone backbone (or 3-hydroxy-2-phenylchromen-4-one) and their diversity results from the dilferent positions of the phenol hydroxyl groups. Carbonyl oxygen in the position 4 formed a hydrogen bond with Cys917 of hVl:GFR2 in all 5 hit flavonols. Also, B3-ring in hit flavonols participated in the hydrophobic interaction. The 5 hits have hydroxyl groups at the 3 -position and 4'-position and these hydroxyl groups participated in hydrogen bonding interactions with Glu915 and Glu1883, respectively. Since galangin and kaempferide do not have 4'-OI I, they were not hit by pharmacophore map. Pachypodol has 4'-OII, but it could not bind to hVEGFR2 owing to the absence of a $3-\mathrm{OH}$. Although myricetin has 3- and $4^{\circ}-\mathrm{OH}$, there are steric conflicts between 5 '-OH of miyricetin and side chains of hydrophobic residues, Val846 and Ala864. LigScore were calculated for five candidate flavonols to predict their binding affinity. ${ }^{27}$ All 5 candidates have similar L.igScore ranged from 5.03 to 5.78 , implying that they can be potent inhibitors of hVEGFR2. Interaction model between flavonol fisetin and hVEGFR2 is shown in Figure 2. Structure of hVEGFR2 in complex with 5 hits and fit model of flavonols with pharmacophore map are represented in Figure 3. The hit llavonols are depicted as stick and transparent surface model.

From the results, we can conclude that 3-and 4'-OH of flavonols are essential for binding to hVEGFR2 and hit flavonols can be potent hVEGFR2 inhibitors with good binding affinities. Characterization of binding modes of llavonols to hVF.GFR2 will be helpful to understand the mechanism of their actions against kinasc.

\section{Conclusion}

We determined a single pharmacophore map which represented the specific interactions between known inhibitors and
hVFGFR2. This map consisted of four leat ures; one HBA, two HBD, and one Lipo. We performed in silico screening for a database including 9 flavonols with the pharmacophore map. Among 9 compounds, 5 flavonols, kacmpferol, querectin, fisetin. morin, and rhamnetin, were hit by pharmacophore map as candidates of hVFGFR2 inhibitors. With no exceptions, hit flavonols have 3- and 4'-OH and these hydroxyl groups participated in hydrogen bonding interactions with ATP binding site of hVEGFR2. We calculated the LigScore of candidate flavonols and proposed that these flavonols can be potent inhibitors of hVFGFR2 with good binding alfinity. This study may provide a strategy for the development of natural flavonoid hVEGFR2 inhibitors as anticancer drugs.

Acknowledgments. This work was supported by the Korea Research Foundation (KRF-2006-005-J03402) and by the Korea Polar Research Institute (KOPRI PE09070). Ki-Woong Jeong is supported, in part, by the second $\mathrm{BK} 2 \mathrm{I}$ (MOE).

\section{References}

I. Ferrara, N.: Gerber. H. P.: LeCouter. J. Nat. Mot. 2003 . 9. 669

2. Isner. J. M.: Asahara. T. J. (Ihn Invest 1999, 103. I231.

3. Kim. M. HI. J. ('ell. Biochem. 2003, 89, 529)

4. Folkman. J.: Shing. Y. J. Biol (hem. 1992. 267. 10431.

5. Klagsbrun, M.: D'Amore. P. A. Anu Row Phwsiol. 1991, 53.217.

6. Emakot a, S. P.: Kang. B. S.: Choi. B. Y.: Choi. H. S . Schuster: T. F.: Ma. W. Y.: Bode, A M.: Dong. Z. (ancer Res. 2006, 60, 9260

7. De Vries. C.: Fiscobedo. J. A.: Ueno. H.: Houck. K.: Fenara. N.: Williams, L. T. Seitence 1992. 255, 989.

8. Shalaby. F.: Rossant. J.: Yamaguchl, T. P.: Gertsenstein, V.: Wu X. -F.: Breltman. M. L: Schuh. A. C. Nature 1995. 376.62.

9. Yang. J. C.: H Laworth. 1.: Shenr. R. M.: I Jwu. P.: Schwarkentruber. D. J.: Topalian. S. L.: Steinberg, S. M.: Chen. H. X.: Rosenberg, S. A. N. tingl J. Med. 2003. 34), 427

10. Drorak. H. F. J. ('/in. (oncol. 2002. 26) 4368 .

II. Ahman. T.: Eisen. T. ('lin. (ancer Res. 2004. /0. $6388 \mathrm{~s}$

12. Sakamoto, K. M. (utr. Optn. Invest. Drtgs 2004, 5, 132\%.

13. Morabito, A: De Maio, E.: Di Maio, M.: Normanno, ... Perrone, F. Oncologist 2006, //, 753.

14. Leone. M.: Zhai. D.: Sareth. S.: Kitada. S.: Reed. J. C.: Pellecchia. M. cancer Res 2003.63.8118

15. Khan, . .: Afaq. F.: Saleem, M.: Ahmad. N.: Mukhtar, H. Cance* Res. 2006, 60. 2500.

16. Chung. J. Y.: Huang. C.: Meng. X.: Dong. Z.: Yang. C. S. Cancer Res. 1999. 50. 4610.

17. Sachinidis. A.; Hescheler. J. Drug News Porspect. 2002. /5. 432.

18. Kiec-Wilk. B .: Dudek, W.: Dembinska-kiec, A. Acto Angiol. 2006. 12.141 .

19. Lu. H.: Chang. D. J.: Baralte. B.: Meijer. L.: Schulse-Gahmen. U. J. Med (hem 2005. + S. 737

20. Baumli. S. Lolli. G.: Lowe. E. D.: Troiani. S.: Rusconi. L: Bullock. A. X.: Debrečeni. J. E.: Knapp. S.: Johnson. L. N. $19130 . J .2008 .27 .1907$

21. Haris. P. A.: Cheung. M. : Hunter. R. N.: Broun. M. L.: Veal. J. M.: Nolte, R. T.: Wang. L.: Liu, W.: Crosby : R. M.: Johnson, J. H.: Epperly. A. H.: Kumar. R.: Luttrell, D. K.: Stafford. J. A. J. Wed ( Them. 2005. $f x .1610$.

22. 11asegawa M.: Nishigaki. ..: Washio. Y.: Kano. K.: Harris. P. A.: Sato. H.: Mori. I.: West. R. I.: Shibahara, M.: Tovoda, H.; Wang, L.: Nolte, R. T.: Veal. J. M.: Cheung M. J. Med chem. 2007. 5\%. 4.53

23. llarmange. J. C.: Weiss. M. M.: Germain. J.: Polverino. A. J.: Borg. G.: Bready. J.: Chen. D.: Choquetle. D.: Coxon. A.: DeMelfi. 
T.: DiPietro, L.: Doen, N.: Estrada, J.: Flym, J.: Graceffa, R. F.: Harriman, S. P.: Kaufman, S.: La, D. S.; Long, A.: Martin, M. W.: Neervannan, S.: Patel, V. F.: Potashman, M.: Regal, K.: Roveto, P. M.; Sclurag, M. L.; Starnes, C.; Tasker, A.; Teffera, Y.; Wang, L.; White, R. D.; Whittington, D. A.; Zanon, R. J. Wed. Chem. $2008,51,1649$.

24. Lee, J. Y., Jung, K. W.: Kin, Y. Bull Korean Chem. Soc. 2008, 29,
1717.

25. Lee, I. Y.: Jung, K. W, Woo, E. R.: Kim, Y. Bull. Korean Chem. Soc. 2008. 29.1479.

26. Rajnaryana, K.; Sripalreddy, M.; Chalavadi, M. R.; Krishna, D. R. Intian J. Phamacol. 2001, 33, 2.

27. Krammer, A.; Kirchhoff, P. D.; Venkatachalam, X. I. C. M.; Waldman. M. J. A fol. Graph. Model. 2005, 23,395. 